\title{
ИССЛЕДОВАНИЕ КОАГУЛЯЦИИ В ПРОЦЕССАХ ОЧИСТКИ СТОЧНЫХ ВОД С ПРИМЕНЕНИЕМ КОМПЬЮТЕРНОЙ ТЕХНОЛОГИИ
}

\section{THE RESEARCH OF THE COAGULATION WITH THE APPLICATION OF COMPUTER TECHNOLOGY TU THE PROCESS OF WASTERWATER TREATMENT}

E. Goncharenko

B. Ksenofontov

S. Berezina

Yu. Borisov

Summary. The following material suggests a computational method which allows assess the efficiency of the industrial coagulants used for water treatment. Tu intensify the process of wasterwater treatment in the work we studied the use floculants microorganisms of activated sludge.

Keywords: water treatment, coagulants, computer technology, activated sludge, flocculants.

\author{
Гончаренко Евгения Евгеньевна \\ К.хим.н., дочент, МГТУ им.Н.Э. Баумана г. Москва \\ eeg84@mail.ru \\ Ксенофонтов Борис Семенович \\ Д.т.н., профессор, МГТУ им.Н.Э. Баумана г. Москва \\ Березина Светлана Львовна \\ К.хим.н., дочент, МГТУ им.Н.Э. Баумана г. Москва \\ Борисов Юрий Александрович \\ К.т.н., доцент, МГТУ им.Н.Э. Баумана г. Москва
}

Аннотация. В работе рассмотрено применение методики, разработанной авторами, с компьютерным вариантом выполнения и обработки данных к процессам очистки сточных вод промышленными коагулянтами, а также к процессам очистки микроорганизмами активного ила.

Ключевые слова: компьютерная технология, очистка воды, коагулянты, активный ил, флокулянты.

графиков. Допускается остановка записи данных в любой момент времени и оперативный просмотр экспериментальных кривых на мониторе, а также сохранение полученных результатов в виде текстовых форматов. Так как в работе использовался метод фотоколориметрического титрования, измерения проводились с помощью двух датчиков: датчика оптической плотности и датчика объема жидкого реагента. Для измерения оптической плотности оптическая кювета с 80 мл дистиллированной воды ставилась на магнитную мешалку. После настройки оборудования в кювету наливалось 80 мл исследуемой дисперсной системы и, вращением рукоятки датчика объема, постепенно добавлялось по 0,2-0,5 мл реагента Методика работы и схема установки подробно описаны в нашей работе [1, с. 3-6], При добавлении каждой порции раствора реагента в компьютер вводился результат измерения оптической плотности. При включении системы измерений в окне измерений появляется экран с системой координат. По оси ординат откладываются значения оптической плотности раствора, по оси абсцисс - объем добавляемого реагента. В правом верхнем углу экрана находятся цифровые индикаторы, численно показывающие соответствующие значения параметров. Таким образом, при проведении работы на экране монитора отображается экспериментально полученная зависимость оптической плотности раствора от объема раствора добавляемого реагента $D=f\left(V_{\text {эл }}\right)$. Эксперимен- 


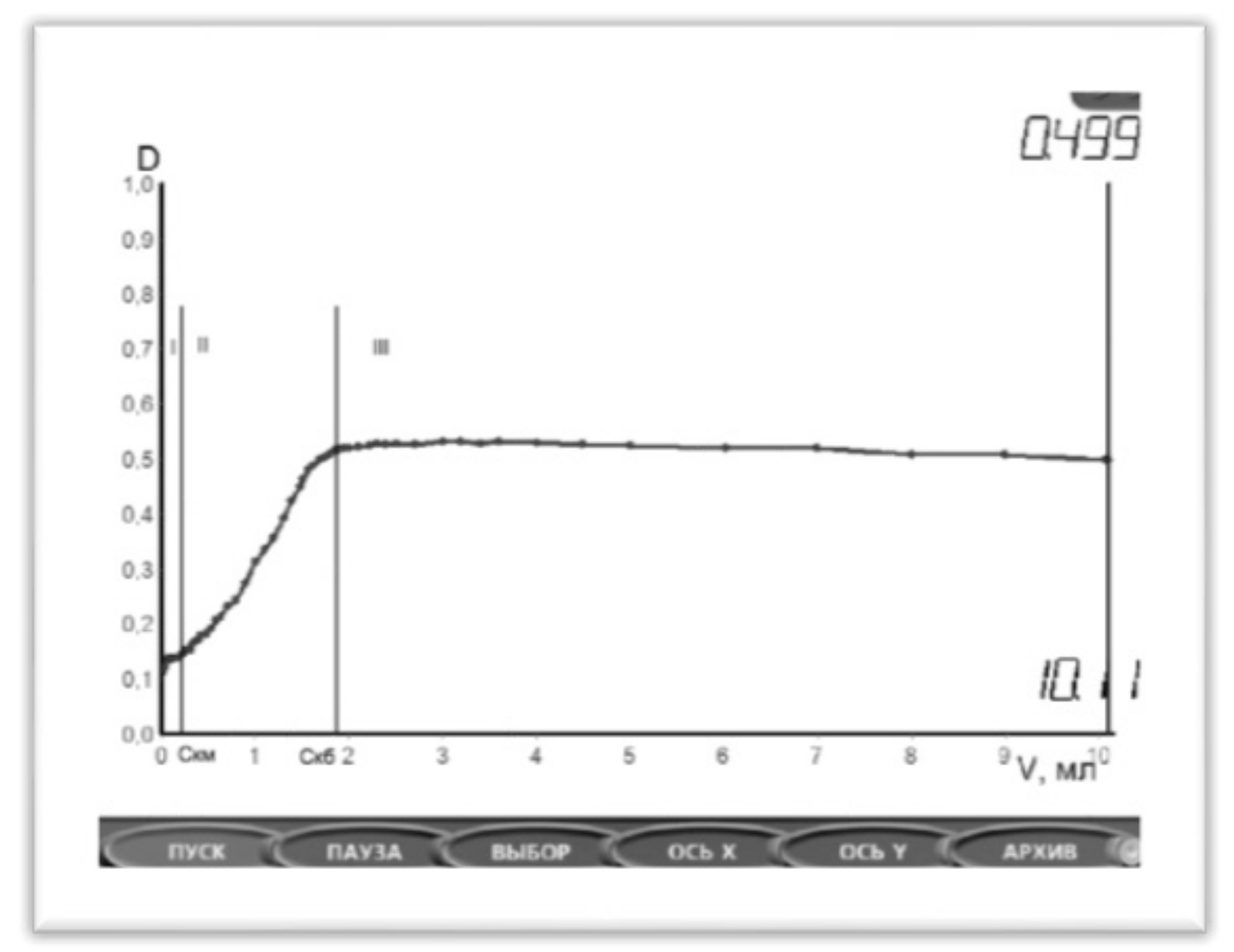

Рис. 1. Зависимость оптической плотности дождевых вод от объема добавляемого реагента 0,5\% раствора «Аква-Аурата 30»

тальные графики на экране монитора при необходимости перестраивались по текстовым форматам. В случае коагуляции по координатам максимума определялся пороговый объем реагента, вызывающий быструю коагуляцию золя [1, с. 7, 10,11].

Данная методика была использована для изучения процессов очистки поверхностных сточных вод. Поверхностные сточные воды содержат примеси жиров, нефтепродуктов, взвешенные в дисперсионной среде частицы тяжелых металлов и их гидроксидов [4]. Постановка такой работы актуальна и особенно важна для условий подтопления и затопления селитебных территорий, то есть территорий, на которых расположены жилые здания, а также площадок предприятий. В этих случаях необходимо в интенсивном режиме проводить отвод и очистку воды [9]. Поэтому в настоящее время большое внимание уделяется разработке комплексных методов очистки сточных вод различного состава с использованием неорганических реагентов, полимерных флокулянтов катионного и анионного типов, а также совместному использованию коагулянтов и флокулянтов [2-5,7]. В работе [1] нами была опробована компьютерная методика на модельных системах. Исследования показали соответствие полученных результатов литературным данным. Однако было отмечено, что воспроизводимость данных наблюдается только при постоянной скорости подачи реагента. Этот результат очень важен ввиду того, что варьируя скорость введения реагента можно изменять агрегативную устойчивость золя. Кроме того, было показано влияние скорости перемешивания системы. Для получения оптимальных результатов градиент скорости перемешивания осветляемой суспензии по нашим данным не должен превышать значений 90-100 c-1.

В качестве объекта исследования в работе использовались токи дождевых вод, собранные на территории, прилегающей к главному корпусу МГТУ им. Н.Э.Баумана. Анализ взятых проб показал, что в них содержатся примеси неорганических веществ в виде сульфатов (99,5 мг/л) и хлоридов (10,5 мг/л), нефтепродукты 
Таблица 1. Порог быстрой коагуляции СКБ и коагулирующая способность Ү растворов «Аква-АуратаТМ30»

\begin{tabular}{|l|l|l|l|}
$\begin{array}{l}\text { Концентрация раствора (С\%) } \\
\text { «АКва-Аурата }\end{array}$ & $\mathbf{V}_{\text {(M0» }}$ (мл) & $\mathbf{C}_{\text {КБ }}$ (моль/л) & $\mathbf{Y}$ (л/моль) \\
\hline 0,5 & 1,8 & 0,0657 & 15,209 \\
\hline 0,25 & 3,3 & 0,0589 & 16,9 \\
\hline
\end{tabular}

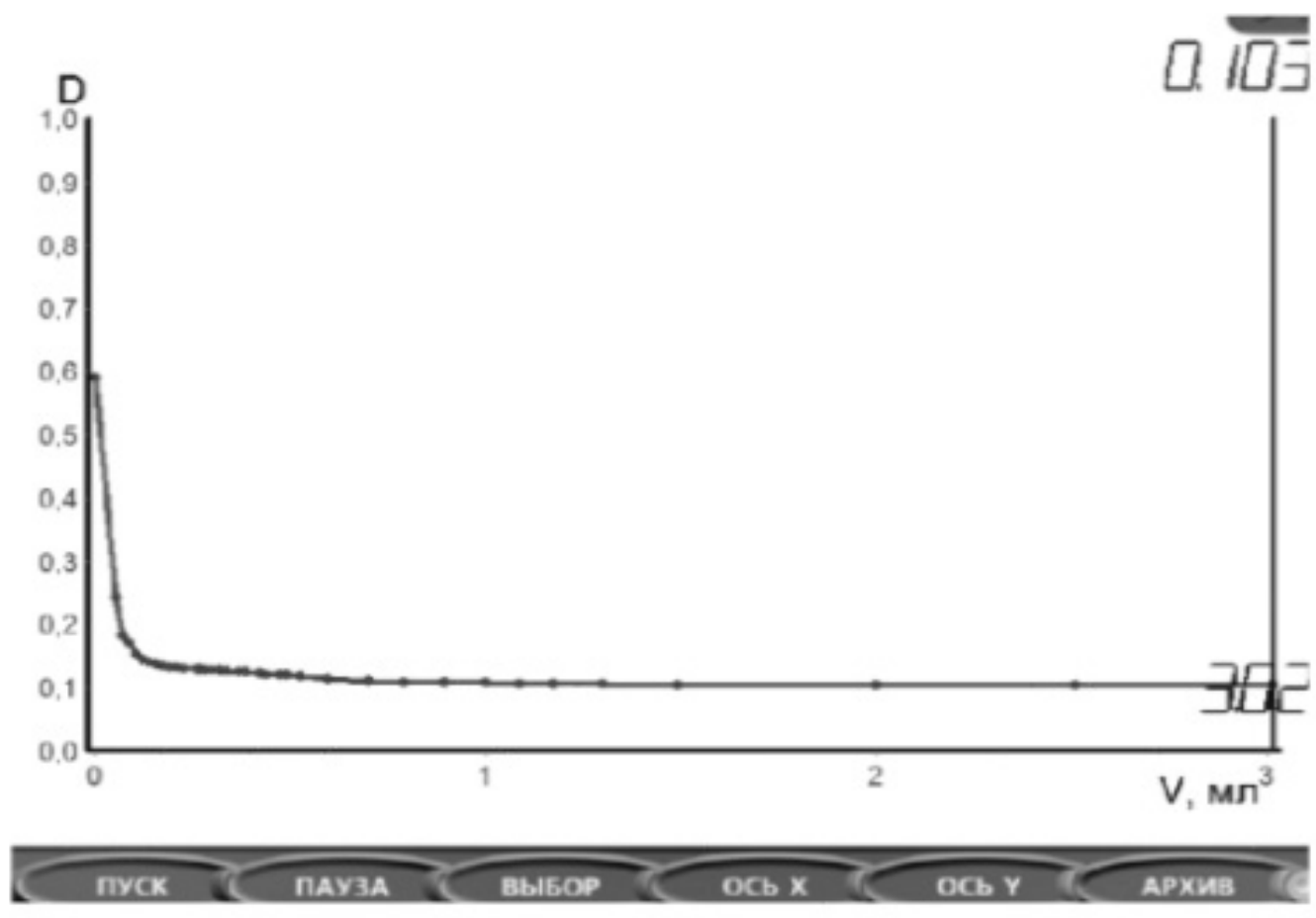

Рис. 2. Очистка тонкодисперсной суспензии отходов лакокрасочной промышленности с концентрацией загрязняющих частиц 0,15 г/л

(0,45 мг/л), взвешенные вещества (28 мг/л), а также небольшие количества металлов: Fe (1,2 мг/л), Zn (0,12 мг/л), $\mathrm{Cr}\left(5 \cdot 10^{-3} \mathrm{Mr} / л\right), \mathrm{Pb}\left(4,8 \cdot 10^{-3} \mathrm{Mr} / л\right)$. Для очистки дождевых вод нами использовались промышленные коагулянты: растворы «Аква-Аурата ${ }^{\mathrm{TM}} 30$ » и сульфата алюминия $\mathrm{Al}_{2}\left(\mathrm{SO}_{4}\right)_{3}$. Растворы «Аква-Аурата ${ }^{\mathrm{TM}} 30$ » с концентрациями 0,1\%, 0,25\%, 0,5\% приготовлялись по стандартной методике [6]. На рис. 1 показана в качестве примера полученная на мониторе экспериментальная зависимость оптической плотности от объема 0,5\% раствора «АкваАурата $^{\mathrm{TM}} 30 »$.

На рисунке 1 отмечено три области протекания процесса: область 1 - зона устойчивости дисперсной систе- мы; область 11 - зона медленной коагуляции; область 111 - зона быстрой коагуляции; $C_{K M}$ - порог медленной коагуляции; $C_{K D}$ - порог быстрой коагуляции. Расчет порога быстрой коагуляции проводился по формуле:

$$
C_{K Б}=\frac{C K V_{K}}{V},
$$

где $\mathrm{V}=\left(\mathrm{V}_{K}+\mathrm{V}_{\partial}\right)$ - объем раствора; $\mathrm{V}_{K}$ - пороговый объем коагулянта; $V_{д}$ - объем исследуемой дисперсной системы (80 мл) $C_{K}$-концентрация введенного реагента (моль/л) $C_{K Б}$ - порог быстрой коагуляции. Пороговый объем $\mathrm{V}_{K}$ определялся по координате точки максимума на экспериментальных кривых. Коагулирующая способность Ү реагента-коагулянта рассчитывалась как величи- 


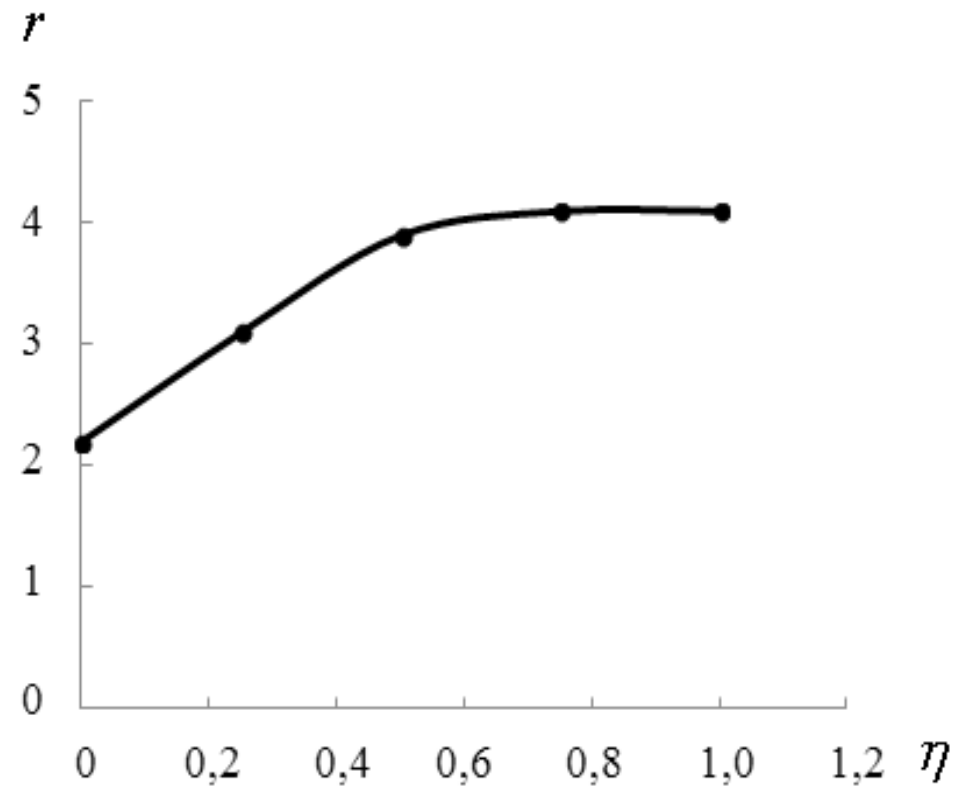

Рис. 3. Зависимость скорости осаждения твердой фазы (м/ч) от расхода микроорганизмов активного ила (г/л стоков)

на, обратная порогу быстрой коагуляции [1, с. 7, 10,11]. Результаты расчета представлены в таблице 1

В работе показано, что при разбавлении раствора «Аква-Аурата ${ }^{\mathrm{TM}} 30$ до концентрации $\mathrm{C}=0,1 \%$ коагуляции не происходит. Таким образом, экспериментальные данные позволяют сделать вывод, что при разбавлении раствора реагента коагулирующая способность возрастает, но до определенного предела. Для сравнения эффективности были проведены опыты с использованием в качестве реагента $5 \%$ раствора $\mathrm{Al}_{2}\left(\mathrm{SO}_{4}\right)_{3}$. Порог быстрой коагуляции в этом случае оказался равен: $C_{K 5}=0,363$ моль/л, а коагулирующая способность Ү равна: = 2,75 л/моль.

Это гораздо ниже коагулирующей способности 0,5\% раствора «Аква-Аурата 30». Компьютерная методика была также опробована в процессе очистки тонкодисперсной суспензии отходов лакокрасочной промышленности с концентрацией загрязняющих частиц 0,15 г/л с использованием в качестве реагента 0, 25\% раствора «Аква-Аурата 30». Полученные данные (рис. 2) позволяют сделать вывод, что коагуляция в данном случае не происходит, так как двойной электрический слой не образуется, а наблюдается осаждение твердой фазы. Эффективность процесса осаждения твердой дисперсной фазы оценивалась по минимальной величине оптической плотности. Как следует из рис. 2, для полного осаждения суспензии лакокрасочных отходов достаточно добавить только 0,3 мл 0.25\% раствора «Аква-Аурата ${ }^{\mathrm{TM}} 30$ ». Таким образом, по характеру получаемых кривых зависимости оптической плотности дисперсной системы D от объема добавленного реагента можно судить о механизме протекающего при водоочистке процесса.

Следует отметить, что использование неорганических реагентов не всегда эффективно, поэтому для интенсификации процесса очистки неорганические коагулянты обычно применяются в сочетании с синтетическими флокулянтами [12]. В качестве флокулянтов используются линейные полимеры с высокой молекулярной массой, несущие полярные группы на обоих концах цепи: полиакриламид, полиоксиэтилен и т.д. Молекула полимера двумя концами присоединяется к двум частицам загрязнений в дисперсионной среде, скрепляя их полимерными мостиками. Таким образом, флокулянты объединяют частицы загрязнений в большие агрегаты - флокулы, что приводит к резкому увеличению скорости осаждения. В тоже время было показано, что для интенсификации процесса очистки сточных вод требуется применение значительного количества реагентов, что приводит к повышению затрат. Поэтому особый интерес представляет использование в качестве биофлокулянта микроорганизмов избыточного активного ила, образующегося при биохимической очистке воды. В процессе биохимической очистке масса активного ила возрастает и ее необходимо утилизировать. Под действием активного ила происходит биохимическое окисление органических примесей, содержащихся в воде, с превращением их в безвредные соединения: диоксид углерода, воду, нитрит и сульфат ионы [2,3]. Эффектив- 
ность использования активного ила как биофлокулянта показана в работах $[7,8,11]$ Нами проведено исследование влияния микроорганизмов активного ила на интенсификацию процесса очистки поверхностных сточных вод. Опыты проводились при комнатной температуре. Микроорганизмы активного ила с концентрацией 8,5 г/л вводились в сгущаемую суспензию.

На рис. 1 представлены данные зависимости скорости осаждения взвешенных частиц твердой фазы в осветляемых сточных водах от расхода микроорганизмов активного ила.

Полученные данные (рис. 3) показывают, что скорость осаждения увеличивается по мере увеличения количества микроорганизмов в суспензии. При этом повышается степень осветления очищаемой воды из-за уменьшения содержания взвешенных частиц.

Оценивая в целом возможности применения микроорганизмов избыточного активного ила в качестве биофлокулянта для очистки сточных вод следует отметить, что финансовые затраты при его использовании связаны только с его транспортировкой. Для транспортировки необходимо предварительное уплотнение избыточ- ного активного ила, которое осуществляется напорной флотацией. При этом следует учесть, что флотационная очистка способствует удалению из сточных вод ПАВ, нефтепродуктов, жиров, смол и др. [7,8].

\section{Выво $\triangle \mathrm{b}$}

1. В работе показана возможность использования разработанной авторами методики с применением компьютерной технологии для очистки поверхностных сточных вод промышленными коагулянтами

2. Проведены исследования по влиянию микроорганизмов активного ила на интенсификацию процесса очистки производственных поверхностных сточных вод. Показано, что при увеличении концентрации микроорганизмов в суспензии активного ила, увеличивается скорость осаждения твердой фазы, и возрастает степень осветления.

3. Показана возможность частичной утилизации избыточного активного ила, образующегося при биологической очистке сточных вод, за счет его использования в качестве биофлокулянта для интенсификации процессов очистки.

\section{ЛИТЕРАТУРА}

1. Гончаренко Е.Е., Ксенофонтов Б. С., Голубев А, М. Исследование устойчивости и коагуляции лиофобных золей с применением компьютерной технологии // Вестник МГТУ им. Н. 3. Баумана. Сер. Естественные науки. 2014. № 1. С. 54-65

2. Хенце М., Армоэс П., Ля-Кур-Янсен, И., Арван Э. Очистка сточных вод. Биологические и химические процессы:- М.: Мир. 2006.480 с. (перевод с англ.).

3. Никитина 0. Г. Современная концепция биологической очистки сточных вод. // Вода: химия и экология. 2009. М. с. 9-20

4. Бабенко Е. Д. Очистка сточных вод коагулянтами. 1977. М. Наука. 356 с.

5. Гвоздев Е.Д., Ксенофонтов Б. С. Очистка производственных сточных вод и утилизация осадков. 1988. М. Химия. 112 с.

6. Сборник Рекомендаций Хельсинской Комиссии: Справочно-методическое пособие.— СПб: Диалог. 2008. 512 с.

7. Ксенофонтов Б.С., Гончаренко Е. Е. Использование активного ила после предварительной флотационной обработки в качестве биофлокулянта. Журнал Экология и промышленность в России. 2018. № 3, с. 10-22

8. Ксенофонтов Б. С. Флотационная обработка воды, отходов и почвы. 2010. М. Новые технологии. 272 с.

9. Рекомендации по расчету систем сбора, отведения и очистки поверхностного стока с селитебных территорий, площадок предприятий и определению условий выпуска его в водные объекты. - М: ОАО

10. Щукин Е.Д., Перцов А. В., Амелина Е. А. Коллоидная химия 2006. М.: Высшая школа. 444 с.

11. Гончаренко Е.Е., Бадаев Ф. 3., Авсинеева Н. К. Устойчивость и коагуляция лиофобных золей. 2011. М: Издательство МГтУ им. Н. Э. Баумана. 48 с.

12. Запольский А. Г. Коагулянты и флокулянты в процессах очистки воды. Свойства. Получение. Применение / А. Г. Запольский, А. А. Баран. - Л. Химия, 1987. - 208 c. 